\title{
DETECCIÓN DE ANTICUERPOS CONTRA PESTIVIRUSEN RUMIANTES DE UNA COMUNIDAD CAMPESINA DE LA PROVINCIA DE CANCHIS, CUSCO
}

\author{
Sonia A Ivarez L I. ${ }^{1}$, Hermelinda Rivera G . ${ }^{2}$, Danilo Pezo C. ${ }^{3}$ y W ilber \\ García V. ${ }^{3}$
}

\section{ABSTRACT}

The seroprevalence of bovine viral diarrhoea virus (BVDV) and border disease virus (BDV) in serumsamples of al pacas $(n=200)$, bovine $(n=38)$ and ovine $(n=45)$ of a rural community of Cusco, Perú was carried out by virus-neutral ization test The $11.5 \pm$ $4.4 \%(23 / 200)$ and $9.5 \pm 4.1 \%(19 / 200)$ of al pacas had neutral izing antibodies against BVD and $B D$ virus. The $73.7 \pm 13.9 \%(28 / 38)$ and $76.3 \pm 13.5 \%$ (29/38) of bovineand the 13.3 $\pm 9.9 \%(6 / 45)$ and $15.5 \pm 10.6 \%(7 / 45)$ of ovinehadantibodiestoBVDV andBDV respectively. Theseresults confim the presence of pestiviral infection in ruminants of amixed breeding systeminarural community.

K ey words: Bovineviral diarrhoea virus, border disease virus, al paca, bovine, sheep, antibodies, virus-neutral ization

\section{RESUMEN}

El presente estudio tuvo como objetivo determinar la seroprevalencia de los pestivinus dela enfermedad dela diarreaviral bovina(DVB) y enfermedad dela frontera (EF) en rumiantes de la comuni dad deSilly, provincia deCanchis, Cusco, a través dela detección de anticuerpos en el suero sanguíneo de al pacas $(n=200)$, bovinos $(n=38)$ y ovinos ( $n=45$ ) hembrasadultas, mediantela pruebadevinus-neutralización. El $11.5 \pm 4.4 \%$ $(23 / 200)$ y el $9.5 \pm 4.1 \%(19 / 200)$ de las al pacas presentaron anticuerpos neutral izantes contralosvirusDVB yEF. El $73.7 \pm 13.9 \%$ (28/38) y $76.3 \pm 13.5 \%$ (29/38) delosbovinos y el $13.3 \pm 9.9 \%(6 / 45)$ y $15.5 \pm 10.6 \%$ (7/45) delos ovinos presentaron anticuerpos contra la DVB y EF, respectivamente. Estos resultados confiman la presencia de la infección pestiviral en rumiantes bajo un sistema de crianza mixto en una comunidad campesina del Cusco.

Palabrasclave: Diarreaviral bovina, enfermedad delafrontera, al pacas, bovinos, ovinos, anticuerpos, virus-neutral ización

\footnotetext{
${ }^{1}$ Práctica privada

${ }^{2}$ Laboratorio de Microbiología y Parasitología, FMV-UNMSM. E-mail: hriverag@vetunmsmedu.pe

${ }^{3}$ Estación Experimental IVITA-Maranganí, FMV-UNMSM
} 


\section{INTRODUCCIÓN}

Los pestivirus constituyen un género de la familia Flaviviridae, conformado por el virus delaDiarrea Viral Bovina(VDVB), el virus dela FiebrePorcina Clásica(VFPC) y el virus de la Enfermedad de la Frontera (VEF); agentes relacionados estructural y antigénicamente que presentan reacciones cnuzadas entreell os (Carlsson, 1991; Sakoda et al., 1999) y causan infecciones entre especies (Becher et al., 1999). El éxito en los rumiantes es debido a su habilidad decruzar la barrera placentaria, invadir el feto y generar una infección persistentequecontinuadurante la vida postnatal, clínicamente inaparente, excretando el virus y diseminándolo a un amplio rango dehospederos Artiodactyla (Becher et al., 1997; Paton et al., 1999).

La transmisión puede ser por inha lación o ingestión de saliva, descarga ocul onasal, orina, heces, leche, secreciones uterinas, fluido amniótico, placenta y semen de animales infectados (Baker, 1995). Los pestivinus poseen un especial tropismo por las células del sistemainmuney células epiteliales de los tractos reproductivo, entérico y respiratorio ocasionando como consecuencia de su replicación en estas células un conjunto de patologías dependiendo de la cepa viral y momento en que ocurrelainfección durante la gestación (Potgieter, 1995).

Estudios serológicos han demostradola presencia de la DVB en al pacas de una empresa asociativa de Puno (Rivera et al., 1987) y de una comunidad campesina con crianza mixta deArequipa(Manchego, 1991), perono ha sido detectado en al pacas criadas bajo un buen sistema demanejo (Risco et al., 1998).

Más del $80 \%$ de los camélidos en el sur del país están en manos depequeños criadores que utilizan el sistema de crianza mixto, el cual promueve la transmisión interespecie de los pestivinus (Rivera et al., 1987). El bajo índicedenatali idad y la mortalidad neonatal constituyen severos probl emas enlacrianzadecamélidos en crianzamixtay el rol de los pestivinus en la presentación de estos probl emas aún no hasido elucidada, por lo queel presentetrabajo tuvo como objetivo determinar la seroprevalencia del VDVB y VEF enal pacas, bovinos y ovinos decrianza mixta en una comunidad campesina.

\section{Material y Métodos}

Animales y muestras

El estudio se realizó en una comunidad campesina deSilly, local izada en la Provincia de Canchis, Cusco. Se utilizaron 200 al pacas, 38 bovinosy 45 ovinos hembras crioIlos adultas, que eran parte del grupo mixto deproducción dela comunidad.

El tamaño muestral para la población de alpacas $(n=200)$ se obtuvo mediante $\mathrm{e}$ método para estimar una proporción a través de la aproximación normal a la distribución normal, utilizando para su cál culo una proporción de 0.14 y un nivel de confianza del 95\%(Manchego, 1991). El número debovinos y ovinos utilizados en el estudio estuvo enfunción delas posibilidades delacomunidad.

Las muestras de sangre fueron obteni das indi vidual mentepor punción delavena yugular utilizando vacutainers, y transporta das al Laboratorio de Microbiología del IVITA-Maranganí dela Facultad de MedicinaVeterinaria(FMV) delaUniversidad $\mathrm{Na}$ cional Mayor deSan Marcos(UNMSM) para la obtención del suero sanguíneo. Las muestras procesadas fueron transportadas al $\mathrm{La}$ boratorio de Virología de la FMV, UNMSM dondefueron manteni das en congelación a $-20^{\circ} \mathrm{C}$ hasta su procesamiento.

\section{Reactivos}

Seutilizaron cultivos primarios decé lulas de cornete nasal de feto bovino (CNB) libres de VDVB y VEF como sistema indicador deprueba deneutralización viral; me 
dios de cultivo MEN (Eagle Minimal Essencial Medium) y L-15 (Leibovitz) (SIGMA) en una proporción 50:50 suplementadas con el $10 \%$ de suero fetal bovino libre deVDVB (SIGMA) y antibióticos. Las cepa "Singer" del VDVB y la cepa Cosbay del VEF, obteni das comercialmente (NVS, AMES-IOWA, USA) fueron utilizadas como antígenos en laprueba deneutralización viral .

Detección de anticuerpos pestivirales

La detección y cuantificación de los anticuerpos contra el VDVB y VEF fue rea lizada separadamente medi antela prueba de neutralización viral segúnel protocolo disponible en el Laboratorio de Virología de la FMV-UNMSM. El título del suero fuela diIución más al ta capaz de neutral izar las 100 $\mathrm{DI}_{50} \mathrm{CC} / 50 \mathrm{\mu l}$ del virus, evidenciado por la ausencia de lesión celular. Títulos del suero iguales o mayores a 1:2 fueron considerados positivosaanticuerpos.

\section{Resultados y Discusión}

El $11.5(23 / 200)$ y $9.5 \%(19 / 200)$ delas al pacas adultas fueron seroreactoras al VDVB yal VEF frentea 73.7 (28/38) y 76.3\% (29/38) en bovinos y 13.3 (6/45) y $15.5 \%$ (7/45) en ovinos, respectivamente (Cuadro 1).

La habilidad delos pestivinus decruzar la barrera de especie (Brownlie et al., 1998) debería ser altamente favorecida en un sistema decrianza mixto pero, al parecer, la infección pestiviral enloscamálidossudamericanos tieneun patrón diferentecomo lo indicael bajo nivel deal pacasseroreactoresal VDVB y VEF, pesea queambos virustuvieron ampliadistribuciónenbovinos del mismorebaño.

La seroprevalencia del VDVB en al pacas resultó similar (11.1\%) a lo reportado por Rivera et al. (1987) y Manchego (1991) hace más de una década. Esta baja seroprevalencia de los pestivirus en al pacas adul tas sugiere la existencia de factores que disminuyen latransmisibilidad viral hacialos camélidos. Algunos de estos factores podrían serladi rectaincidenciadelos rayos ultravioleta que no permitiría la sobrevivencia viral, así como el sistema de pastoreo en donde los bovinos pastan primero seguido por las al pacas y después los ovinos.

No hay duda de la susceptibilidad de las al pacas a los pestivinus como lo demuestran los estudios de Rivera et al. (1987) y Manchego (1991), pero al parecer el mecanismo delainfección pestiviral en las al pacas difieredelos otrosrumiantes pues usual mente cuando el VDVB ingresa a un hato de bovinos susceptibles sedifunde rápi damente, los animales seroconvierten y los anticuerpos perduran en nivel es detectables por un tiempo largo (Fredriksen et al., 1999).

Se pudo determinar que más del $30 \%$ de las al pacas presentaron títul os de anticuerpos contra el VDVB y VEF mayores a 1:256 (Cuadros 2 y 3) los cuales en animales no vacunados son consi derados títul os altos y significan un continuo desafío o infecciones recientemente adqui ridas a partir de animales infectados como lo indica Luzzago et al. (1999). En este caso es probable que la infección provenga a partir de los bovinos, ya queesta especiees la principal fuente de infección a otras especies (Carlsson, 1991; Paton etal., 1999) o durante las exposiciones de al pacas, bovinos u ovinos en las ferias comunal es en donde son confinados animal es de diversos estados sa nitarios.

El permanente estado de estrés debido a fallas nutricionales, carga parasitaria, manejo deficiente etc., podrían estar favoreciendo la circul ación delos pestivirus DVB y EF en los bovinos de la comunidad como lo indican los títul os deanticuerpos detectados quevan desde 1:8 hasta mayoresa 1:256 para el caso del VDVB (Cuadro 2) y con ligeras variaciones en el caso del VEF (Cuadro 3), sugiriendo diversos grados de exposiciones delos bovinosy ovinos a ambos virus. 
Cuadro 1. Seroprevalencia de los virus de la Diarrea Viral Bovina (DVB) y Enfermedad de la Frontera (EF) en rumiantes de crianza mixta, mediante la prueba de neutralización viral

\begin{tabular}{|c|c|c|c|c|c|}
\hline \multirow{2}{*}{ Especie } & \multirow{2}{*}{$\mathrm{N}^{\circ}$ Animales } & \multicolumn{2}{|c|}{ Positivos a DVB } & \multicolumn{2}{|c|}{ Positivos a EF } \\
\hline & & $\mathrm{N}^{\circ}$ & $\%$ & $\mathrm{~N}^{\circ}$ & $\%$ \\
\hline Alpacas & 200 & 23 & 11.5 & 19 & 9.5 \\
\hline Bovinos & 38 & 28 & 73.7 & 29 & 76.3 \\
\hline Ovinos & 45 & 6 & 13.3 & 7 & 15.5 \\
\hline
\end{tabular}

Cuadro 2. Distribución de los títulos deanticuerpos contra el VDVB en muestras desuero de rumiantes mediantela prueba deneutralización viral

\begin{tabular}{lccccccccc}
\hline \multirow{2}{*}{ Especie } & Positivos & \multicolumn{4}{c}{ Inversa dela dilución de los títulos deanticuerpos } \\
\cline { 2 - 10 } & $\%$ & 2 & 4 & 8 & 16 & 32 & 64 & 128 & $\geq 256$ \\
\hline Alpacas & 11.5 & 0 & 0 & 0 & 0 & 3 & 3 & 9 & 8 \\
Bovinos & 73.7 & 0 & 0 & 3 & 5 & 5 & 5 & 5 & 5 \\
Ovinos & 13.3 & 1 & 0 & 2 & 1 & 0 & 0 & 0 & 2 \\
\hline
\end{tabular}

Cuadro 3. Distribución de los títulos de anticuerpos contra el VEF en muestras desuero de rumiantes mediantela prueba de neutralización viral

\begin{tabular}{lcccccrrrrr}
\hline \multirow{2}{*}{ Especie } & Positivos & \multicolumn{7}{c}{ Inversa dela dilución delos títulos de anticuerpos } \\
\cline { 2 - 11 } & \multicolumn{1}{c}{$\%$} & 2 & 4 & 8 & 16 & 32 & 64 & 128 & $\geq 256$ \\
\hline Alpacas & 9.5 & 1 & 1 & 0 & 0 & 1 & 2 & 7 & 7 \\
Bovinos & 76.3 & 0 & 0 & 0 & 8 & 3 & 10 & 2 & 6 \\
Ovinos & 15.5 & 0 & 0 & 1 & 3 & 0 & 0 & 1 & 2 \\
\hline
\end{tabular}

Enel presenteestudioseutilizólacepa Cosbay (VEF) como antígeno para detectar anticuerpos contra el VEF en las tres especies de rumiantes de la comuni dad, esperándose encontrar en el ovino una preval encia mayor o igual al reportado en el bovino (76.3\%), pero sólo el $15.5 \%$ de ovinos fueron reactores al VEF. Esta diferencia frente al bovino podríaser debido al escaso número demuestras o queed VEF no está muy difundido en los ovinos dela comunidad.
La alta prevalencia del VEF en los bovinos no podría deberse necesariamentea la mayor susceptibilidad del bovino al VEF, sino a la similitud antigénica entre las cepa Cosbay y lacepa delaDVB utilizadas como antígenos, ya que al gunas cepas del VEF y VDVB poseen homologías en sus secuencias de nucleótidos (hasta de 76\%, Sullivan et al., 1994). Esto podría explicar en parte los similares porcentajes deseroreactoresencontrados en cada especie estudiada (Fig.1). 


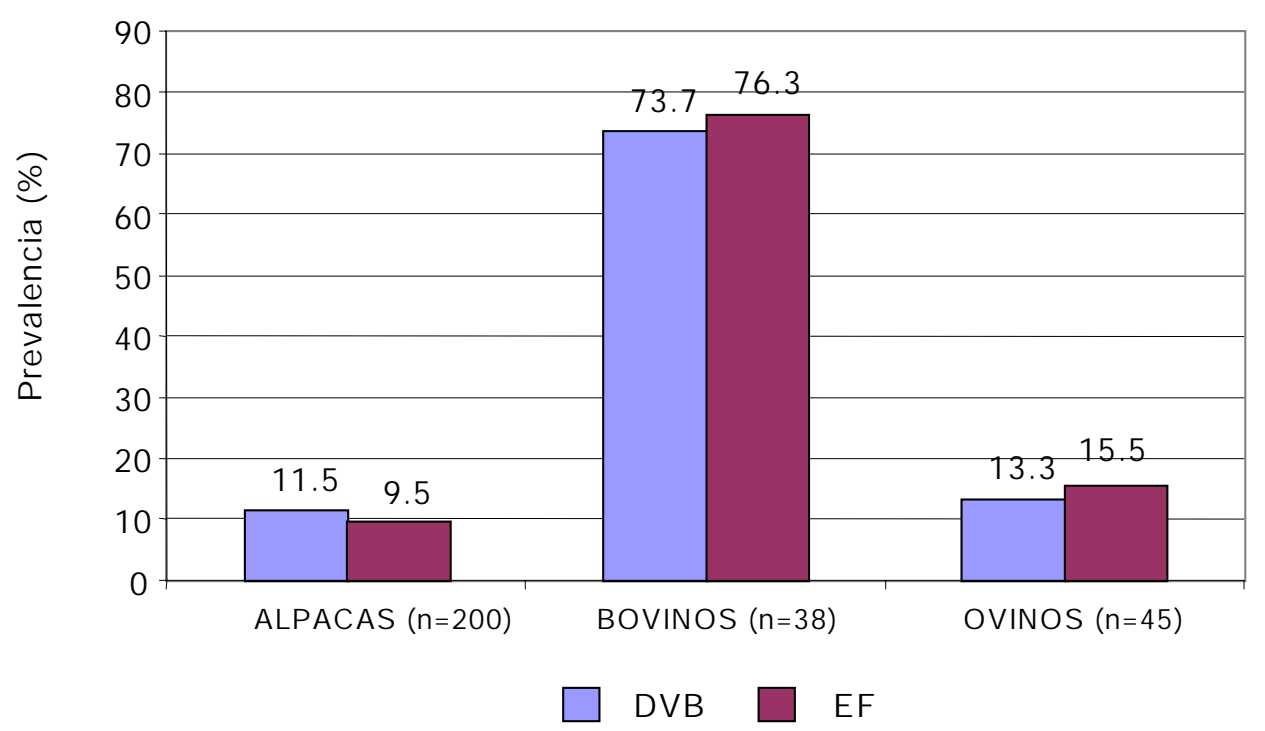

Figura 1. Seroprevalencia de los virus de la Diarrea Viral Bovina y Enfermedad de la Frontera en rumiantes de crianza mixta

La distribución de los títul os de anticuerpos contra el VEF sugieren igual mente una actividad viral en la población deovinos estudia dos pero al parecer menos intensa que en $\mathrm{el}$ bovino y al pacas (Cuadro 3).

Los datos recogidos directamente de los campesi nos dela comuni dad, por no existir registros dela situación sanitaria, indican que la enterotoxemia es una de las principales causas de la mortalidad neonatal en las al pacas. Sin embargo, los problemas respira torios y diarreicos, y los nacimientos decrías débiles son preval entes en la comunidad, sur perando al $24 \%$ reportado en sistemas con buen manejo sanitario (Risco et al., 1998).

Las seroprevalencias de 11.5 y $9.5 \%$ de los VDVB y VEF en al pacas de la comur nidad de Silly sugieren que estos pestivinus no tendrían mayor responsabilidad en los diversos problemas deorden sanitario queafecta al rebaño de la comunidad. Sin embargo, no debe descartarse su asociación con las pérdi das embrionarias o fetal es y mortal idad neonatal, que tienen una alta incidencia, especial mente en los animales de las comunidades campesinas.
No se dispone de datos sobre la seroprevalenciadelaDVB en bovinos delas comunidades previamenteestudiadas pero la prevalencia de la DVB encontrada en los bovinos dela comunidad deSilly essimilar a lo reportado en las cuencas lecheras como Lima, Cajamarca, Arequipa y el Valle del Mantaro quesuperan el 70\% (Rivera H., datos no publicados; Contreras et al., 2000). Así mismo, es similar a otros países como Polonia (83\%), países escandinavos (55 a $100 \%$ ), Reino Unido (62.5\%), Estados Unidos (65\%), Italia (71.2\%), Chile (50\%), etc., indicando que este virus esta ampliamente distribuido en la población bovina mundial (Houe, 1999; Luzzago etal., 1999; Nuotio et al., 1999).

\section{CONCLUSiOnes}

Sedetectaronanticuerpos neutralizantes contralos pestivinus dela diarreaviral bovina (DVB) y enfermedad de la frontera (EF) en los rumiantes (al pacas, bovinos y ovinos) de la comuni dad campesina de Silly, provincia deCanchis, Cusco bajo el sistema decrianza mixto con escasa tecnología. 
La población de bovinos estudiados presentó el mayor número porcentual dereactores tanto para la enfermedad de la diarrea viral bovina y enfermedad delafrontera, que los ovinos y al pacas examinadas.

\section{Literatura CitAdA}

1. Baker, J.C. 1995. The clinical manifestations of bovine viral diarrhea infection. Vet. ClinicsN.A. FoodAnimal Practice 11: 425-445.

2. Becher, P.; M. Orlich; A. Shannon; G. Horner; M. Konig. 1997. Phylogenetic analysis of pestivinuses fromdomesticand wild ruminants. J. Gen-Virology 78: 13571366.

3. Becher, P.; M. Orlich; A. Kosmidou; M. Konig; M. Baroth; H. Thiel. 1999. Genetic diversity of pestivinuses: identification of novel groups and implications for classification. Virology 262: 64-71.

4. Brownlie, J .; L. Hooper; I. Thompson; M.Collins. 1998. Maternal recognition of foetal infection with bovinevinus diarhoed virus(BVDV) - thebovinepestivinus. Clinical and Diagnostic. Virology 10: 141-150.

5. Carlsson, U. 1991. Border disease in sheepcaused by transmission of virusfrom cattle persistently infected with bovinevirusdiarhoeavinus. Vet Rec. 128: 145-147.

6. Contreras, G.; K. Stahl; C. Arana; H. Rivera. 2000. Anticuerpos contra el virus dela diarrea viral bovinaen muestras delechede bovinos del valledel Mantaro (Jauja, Concepcióny Huancayo). Rev. Inv. Vet Penú 11: 58-65.

7. Fredriksen, B.; T. Sandvik; T. Loken; S.A. Odegaard. 1999. Level and dura tion of serumantibodies in cattleinfected experimental ly and naturally with bovine virus diarrhoea virus. Vet Rec. 114: 111114.

8. Houe, H. 1999. Epidemiological features and economical importance of bovinevirus diarrhoea virus (BVDV) infections. Vet. Microbiol. 64: 89-107.
9. Luzzago, C.; R. Piccinini; A. Zepponi; A. Zecconi. 1999. Study on prevalence of bovine viral diarrhoea virus (BVDV) antibodies in 29 Italian dai ry herds with reproductive problems. Vet. Microbiol. 64: 247-252.

10. Manchego, A. 1991. Seroprevalencia de enfermedades viral es en un rebaño mixto deuna comuni dad al paqueraaltoandina de la región Arequipa. Tesis Bachiller, Fac. Med. Vet, Univ. Nac. Mayor San Marcos, Lima. $79 \mathrm{p}$.

11. Nuotio, L.; M.J uvonen; E. Neuvonen; L. Sihvonen; J . Husu-Kallio. 1999. Prevalenceand geographic distribution of bovine viral diarrhoea (BVD) infection inFinland 1993-1997. Vet Microbiol. 64: 231-235.

12. Paton, D.; G. Sharp; G. I bata. 1999. Foetal cross-protection experiments be tween type 1 and type 2 bovine viral diarrhoea virus in pregnant ewes. Vet. Microbiol. 64: 185-196.

13. Potgieter, L. 1995. Inmunology of bovineviral diarnheavinus. Vet ClinicsN.A. FoodAnimal Practice 11: 501-519.

14. Risco, V.; H. Rivera; D. Pezo; W. García; R. Rosadio. 1998. Detección de anticuerpos y virus delaDVB enalpacas durante una campaña reproductiva Rev. Inv. Pec. IVITA (Perú) (№ Extraordinario) 9 (2): 59-64.

15. Rivera, H.; B. Madewell; R. Ameghino, 1987. Serologic survey of viral antibodies inthePeruvianal paca (Lama pacos). Am J. Vet Res. 48: 189-191.

16. Sakoda, Y.; S. Ozawa; S. Damrongwatanapokin; M. Sato; K. I shikawa; A. Fukusho. 1999. Genetic heterogeneity of porcineand ruminantpestivinuses mainly isolated inj apan. Vet Microbiol. 65: 75-86.

17. Sullivan, D.; G. Chang; D. Trent,; R. Akkina. 1994. Nucleotide sequence analysis of thestructural genecoding re gion of the pestivirus border disease virus. Virus Research 33: 219-228. 